\title{
Teachers' Burnout and Work Behavior: The Role of Identity Development and Decision-Making Process
}

\author{
Monica Pellerone, Nicola Malizia, Tiziana Ramaci \\ Kore University of Enna, Enna, Italy
}

\begin{abstract}
Recent studies have confirmed that the category of teachers is subject to numerous and heavy pressures, in particular, covering the peculiarity of the profession, the transformation of society towards a more multiethnic and multicultural lifestyle, the continuous evolution of the perception of social values, the scientific and technological evolution, the greater participation in decisions from students and parents, the need to work in teams, and the lost of social recognitions. The purposes of the present study were to investigate the relation among identity development, decision-making process, and burnout, and measure the predictive variables of the burnout level in a group of 80 Italian teachers, aged 34 to 63 years $(\mathrm{M}=48.85 ; S D=7.40)$. The group completed the following instruments: Link Burnout Questionnaire (LBQ), Ego Identity Process Questionnaire (EIPQ), and General Decision-Making Style (GDMS). Results confirm that burnout seems to be correlated with identity development and decision-making styles. The results suggest future research directions, exploring the differences among different kinds of helping professions' workers.
\end{abstract}

Keywords: identity development, decision-making, burnout, teacher

\section{Introduction}

Individuals create in their mind a representation of external reality (Kelly, 1955), that is, the perceptive lens through which they interpret the environment, in which they are acting in a creative and transformative way on the events, trying to find a right congruence between these and their own needs. Sometimes, thoughts, expectations, hopes, commitment, and motivation of working subjectivity crumble, despite the membership in an inter-subjective system (Avallone \& Farnese, 2005). In such circumstances, individuals may perceive that their energies are completely consumed and absorbed by work commitments - starting a working day with the feeling of being already tired and lacking resources, or even worse, perceiving a kind of futility to the point of feeling totally insensitive to the discomfort and requests of help from others.

When this condition is not temporary, but becomes chronic over time, it can cause a state of intense discomfort to employees, which impedes them from being professionally efficient, and determines the burnout syndrome (Malizia, 2016).

Some categories of workers, because of stressful factors related to the professional activity, are more prone to be at risk than others, regarding the burnout syndrome. This condition results from a particular form of professional discomfort, which is the outcome of a chronic stress that affects mostly people engaged in helping

Monica Pellerone, P.h.D., Psychoterapist, assistant professor, Faculty of Human and Social Sciences, Kore University of Enna. Nicola Malizia, assistant professor, Faculty of Human and Social Sciences, Kore University of Enna.

Tiziana Ramaci, assistant professor, Faculty of Human and Social Sciences, Kore University of Enna. 
professions. It is characterized by physical and emotional fatigue, crisis of identity, feelings of powerlessness to solve problems, aloof and apathetic attitude in interpersonal relations, indifference, suspiciousness, hostility, and feeling of frustration (Malizia, 2016).

\section{The Burnout Syndrome of Teachers}

The literature has shown that this disease is a phenomenon of international scope, which occurs frequently among teachers. One or more stressful conditions, when particularly intense or prolonged, can induce the occurrence of this syndrome (Maslach \& Jackson, 1981). The burnout is considered as a transactional process, triggered by an imbalance between resources and demands, which endures over time, leading to feelings of tension and anxiety, and the change of attitude towards users. In this process, the workers, who have previously given evidence of professionalism and involvement, are disengaged from their work in response to stress and tension experienced, in which case, such stress cannot be relieved by means of an active solution (Santinello \& Altonoè, 2007).

Maslach and Goldberg (1998) argued that the need to think of burnout not only in terms of negative symptoms, but also as a continuum, where, at the positive side, there is the construct of the dedication to work (engagement), or the individual's willingness to work with great energy (energy), be emotionally involved (involvement), and feel effective in his own work (efficacy).

The burnout reaches its peak when subjects in order to address the occupational stress, separate themselves psychologically from work, and become apathetic, cynical, and rigid. We are witnessing, as Edelwick and Brodsky (1980) affirmed, the loss of the motivational impetus, which before, instead, used to push to respond as effectively as possible to users' requests. Pines, Aronson, and Kafry (1981) argued that the burnout is characterized by physical exhaustion, feelings of helplessness, despair, emotionally draining, and negative attitudes toward work, life, and people, and above all, by a reduced identity development (Pellerone, 2014; Pellerone, Passanisi, \& Bellomo, 2015).

Recent literature, in particular, shows that workers with a greater identity development (characterized by high level of identity exploration and commitment) get a more optimal professional profile, characterized by low emotional exhaustion and high professional commitment, compared to subjects with reduced identity development (characterized by low level of identity exploration and commitment), who show higher levels of emotional exhaustion (Luyckx, Duriez, Theo, Klimsta, \& De Vitte, 2010).

\section{Identity Development, Decision-Making, and Burnout in Teachers}

International literature shows that the category of teachers is mostly subject to heavy pressures (Pithers \& Fogarty, 1995), covering, in particular, the peculiarity of the profession, the transformation of society towards a more and more multiethnic and multicultural lifestyle, the continuous evolution of the perception of social values, the scientific and technological evolution, the continuous succession of reforms, the greater participation in decisions by students and parents, the loss of teachers' prestige, the need to work in teams, and the lost of social recognition.

Although the burnout has been primarily designed as a condition that depends, first of all, on the organizational factors, "Some studies have found that personality variables can be predisposing factors to the onset of the syndrome" (Di Nuovo \& Commodari, 2004, p. 45). Individual factors include personality traits, career goals, previous experience, and decision-making skills. Similarly, among the personality traits, there are 
the following dimensions: anxiety, locus of control, introversion or extroversion, and flexibility or stiffness of the subject (Specchiale et al., 2013).

In particular, Maslach and Jackson (1984) showed the presence of a correlation among personality traits, personal expectations, work motivation, and burnout. According to the authors, the person most at risk is weak and submissive in relationships with others, subdued and anxious, prone to give in to user's requests, sometimes impatient and intolerant, prey to anger and frustration, hostility towards others, often lacking in confidence, reserved, conventional, and condescending.

Not all people are equally exposed to the burnout, because the subjective efficacy and ability to make decisions represent protective factors for the manifestation of the syndrome. In particular, the workers with a high self-efficacy will perceive professional difficulties as challenges, in the face of which they have to emphasize and enhance the commitment, and the failures as learning opportunities and incentives to improve. Conversely, the workers with low personal effectiveness will be led to see the difficulties as insurmountable obstacles and tend to procrastinate or surrender the important choices, and in front of the uncertain situations, they will be led to put less effort and have less and less self-confidence (Dworkin, Saha, \& Hill, 2003).

\section{Objective and Hypotheses}

Starting from these premises, the present study considers level of burnout as a key variable to explain relationship with decision-making and identity style, in order to improve the quality of life. The study built on and extended the previous research, considering the role stress disorders of teachers, while they are in workspace. The purposes of this study were to investigate the relation among identity development, decision-making process, and burnout, and measure the predictive variables of the burnout level in a group of Italian teachers.

In particular, the following hypotheses are proposed:

Hypothesis 1 . The burnout level correlates negatively with identity development;

Hypothesis 2. The burnout level correlates positively with the avoidant decision style and negatively with spontaneous and rational decision styles;

Hypothesis 3. The burnout level is predicted of the following dimensions: elevated age, reduced use of the rational style, and elevated importance given to occupation, personal values, and gender roles.

\section{Methodology}

\section{Subjects}

A total of 80 women, chosen through a random selection process, completed an anonymous self-report questionnaire. The participants were Italian teachers (females), belonging to two middle Sicilian schools, aged 34 to 63 years $(\mathrm{M}=48.85 ; S D=7.40)$.

\section{Instruments}

The following instruments were administered to all group of participants.

Link Burnout Questionnaire (LBQ). LBQ (Santinello \& Altoè, 2007) is a self-report questionnaire consisting of 24 items, summarized in four factors: (a) psychophysical exhaustion. It refers to feel tense, under pressure and without energy; (b) detriment of relationships. It describes the quality of relationship between 
employees and their clients. This relationship is characterized by insensibility and distance form clients' problems; (c) professional inefficacy. It includes the lack of gratifications by own work; and (d) disillusion. In fact, burnout is considered as the arrival of a long disillusion process, in which the expectations toward the work have been totally disregarded.

Ego Identity Process Questionnaire (EIPQ). EIPQ (Balistreri, Busch-Rossnagel, \& Geisinger, 1995) is a tool that investigates identity status development according to Marcia's model through the dimensions of exploration and commitment. The exploration level is measured through the analysis of four ideological domains (occupation, religion, politics, and values). The commitment level is investigated through four interpersonal domains (family, friendships, gender roles, and sentimental relationships).

General Decision-Making Style (GDMS). GDMS (Scott \& Bruce, 1995) is a questionnaire constructed for detecting individual decision style. It consists of 25 items grouped into five subscales corresponding to five decision styles: rational (deep search for information and systematic evaluation of alternatives), intuitive (confidence in one's own intuitions and feelings), dependent (search for advice and opinions from people that are considered competent), avoidant (attempt to avoid decision-making), and spontaneous (making the choice in the shortest possible time).

\section{Data Analysis}

Data are analyzed with multivariate methods that enabled the statistical control on individual variables. The participants were personally informed about the nature and purpose of the study. All the analyses were carried out using Statistic Package for Social Science (SPSS) (version 23.0) software package.

The univariate analyses of variance (ANOVA one-way) were used in order to evaluate the influence of the age variable on identity development, decision-making style, and levels of burnout. The correlation analyses were conducted in order to value the first two research hypotheses. A multiple regression analysis was used to measure the third research hypothesis.

\section{Results}

In reference to the identity development, the preliminary analysis shows that the age seems to influence all dimensions of identity (see Table 1). In particular, the mean scores show that the older teachers seem to give higher priority to religion, politics, and family than younger teachers, who seem to give more importance to the dimensions related to occupation, values, friendship, sentimental relationships, and gender roles.

Table 1

The Influence of Age on the Identity Development

\begin{tabular}{llr}
\hline Measures & $F$ & $p$-value \\
\hline Occupation & 1.926 & 0.022 \\
Religion & 4.541 & $<0.001$ \\
Politisc & 2.313 & 0.005 \\
Value & 2.808 & 0.001 \\
Family & 2.463 & 0.003 \\
Friendship & 2.763 & 0.001 \\
Gender roles & 3.903 & $<0.001$ \\
Sentimental relationships & 4.732 & $<0.001$ \\
\hline
\end{tabular}


In reference to the decision-making process, the analysis underlines that age seems to affect all decision styles (see Table 2). The mean scores show that the older teachers seem predominantly use the rational and intuitive styles, but the younger teachers tend to use the dependent, avoidant, and spontaneous styles.

Table 2

The Influence of Age on the Decision-Making Styles

\begin{tabular}{llc}
\hline Measures & $F$ & $p$-value \\
\hline Rational style & 2.687 & 0.001 \\
Dependent style & 5.338 & $<0.001$ \\
Avoidant style & 3.462 & $<0.001$ \\
Intuitive style & 4.716 & $<0.001$ \\
Spontaneous style & 3.190 & $<0.001$ \\
\hline
\end{tabular}

Similarly, another preliminary analysis shows the influence of age on all burnout dimensions (see Table 3). In particular, the older teachers seem to show higher levels of burnout than younger.

Table 3

The Influence of Age on Burnout

\begin{tabular}{llr}
\hline Measures & $F$ & $p$-value \\
\hline Psychophysical exhaustion & 2.081 & 0.012 \\
Detriment of relationships & 4.881 & $<0.001$ \\
Professional inefficacy & 2.549 & 0.002 \\
Disillusion & 1.811 & 0.034 \\
\hline
\end{tabular}

Confirming the first research hypothesis (see Table 4), the Pearson's correlation shows a negative relation between the identity commitment and the detriment of relationships $(r=-0.272, p<0.05)$.

Table 4

Correlation Between Identity Development and Burnout

\begin{tabular}{|c|c|c|c|c|c|}
\hline Measures & $\mathrm{a}$ & $\mathrm{b}$ & $\mathrm{c}$ & $\mathrm{d}$ & $\mathrm{e}$ \\
\hline a. Identity exploration & - & & & & \\
\hline b. Identity committment & $0.243^{*}$ & - & & & \\
\hline c. Psychophysical exhaustion & 0.219 & -0.178 & - & & \\
\hline d. Detriment of relationships & 0.059 & $-0.272 *$ & $0.681^{* *}$ & - & \\
\hline e. Professional inefficacy & 0.058 & -0.061 & $0.582^{* *}$ & $0.501^{* *}$ & - \\
\hline f. Disillusion & 0.016 & 0.037 & $0.520^{* *}$ & $0.583^{* *}$ & $0.339^{* *}$ \\
\hline
\end{tabular}

Note. ${ }^{* *} p<0.01 ;{ }^{*} p<0.05$.

Confirming to the second research hypothesis, the Pearson's correlation underlines that the rational style correlates negatively with the following subscales of the burnout: psychophysical exhaustion, detriment of relationships, and disillusion. Furthermore, the avoidant style is positively correlated with exhaustion, detriment, and professional inefficacy. Finally, the spontaneous style correlates positively with exhaustion and professional inefficacy (see Table 5).

In order to explore the predictive variables to the burnout level, four multiple regression analyses were conducted. The first shows that predictors of the psychophysical exhaustion are religion, politics, value, family, gender roles, and the following type of decision styles, rational, avoidant, and intuitive (see Table 6). 
Table 5

Correlation Between Identity Development and Burnout

\begin{tabular}{lllllllll}
\hline Measures & $\mathrm{a}$ & $\mathrm{b}$ & $\mathrm{c}$ & $\mathrm{d}$ & $\mathrm{e}$ & $\mathrm{f}$ & $\mathrm{g}$ & $\mathrm{h}$ \\
\hline a. Rational style & - & & & & & & & \\
b. Dependent style & $0.339^{* *}$ & - & & & & & & \\
c. Avoidant style & -0.023 & $0.349^{* *}$ & - & & & & & \\
d. Intuitive style & 0.180 & -0.051 & 0.099 & - & & & & \\
e. Spontaneous style & 0.087 & 0.184 & $0.548^{* *}$ & $0.359^{* *}$ & - & & & \\
f. Psychophysical exhaustion & $-0.289^{* *}$ & 0.092 & $0.347^{* *}$ & 0.166 & $0.331^{* *}$ & - & & \\
g. Detriment of relationships & $-0.392^{* *}$ & -0.150 & $0.357^{* *}$ & 0.069 & $0.268^{*}$ & $0.681^{* *}$ & - & $0.501^{* *}$ \\
h. Professional inefficacy & -0.057 & 0.140 & $0.573^{* *}$ & 0.209 & $0.487^{* *}$ & $0.582^{* *}$ & $0.539^{* *}$ \\
i. Disillusion & $-0.491^{* *}$ & -0.220 & 0.075 & 0.208 & 0.183 & $0.520^{* *}$ & $0.583^{* *}$ & 0.333 \\
\hline
\end{tabular}

Note. ${ }^{* *} p<0.01$.

Table 6

Model Summary of Hierarchical Regression Analysis That Predicts the Exaustion in All Group

\begin{tabular}{|c|c|c|c|c|c|c|}
\hline Measures & $R^{2}$ & Adjusted $R^{2}$ & S.E. & $B^{*}$ & $T$ & $p$-value \\
\hline Age & 0.720 & 0.660 & 0.052 & -0.090 & -1.187 & 0.240 \\
\hline Occupation & & & 0.212 & -0.006 & -0.067 & 0.947 \\
\hline Religion & & & 0.167 & 0.224 & 2.868 & 0.006 \\
\hline Politics & & & 0.219 & -0.183 & -2.023 & 0.047 \\
\hline Value & & & 0.202 & 0.195 & 2.437 & 0.018 \\
\hline Family & & & 0.168 & -0.486 & -6.149 & 0.000 \\
\hline Friendship & & & 0.178 & 0.068 & 0.794 & 0.430 \\
\hline Gender roles & & & 0.155 & 0.413 & 4.598 & 0.000 \\
\hline Sentimal relationships & & & 0.209 & -0.112 & -1.129 & 0.263 \\
\hline Rational style & & & 0.155 & -0.336 & -3.516 & 0.001 \\
\hline Dependent style & & & 0.116 & 0.105 & 1.222 & 0.226 \\
\hline Avoidant style & & & 0.143 & 0.330 & 2.985 & 0.004 \\
\hline Intuitive style & & & 0.163 & 0.247 & 2.634 & 0.011 \\
\hline Spontaneous style & & & 0.052 & -0.090 & -1.187 & 0.240 \\
\hline
\end{tabular}

Note. ${ }^{*} B=$ beta standardized coefficients.

The second regression analysis underlines that the predictive variables of the detriment are the following: value, family, and the rational and avoidant styles (see Table 7).

Table 7

Model Summary of Hierarchical Regression Analysis That Predicts the Detriment in All Group

\begin{tabular}{|c|c|c|c|c|c|c|}
\hline Measures & $R^{2}$ & Adjusted $R^{2}$ & S.E. & $B^{*}$ & $T$ & $p$-value \\
\hline Age & 0.564 & 0.470 & 0.066 & -0.083 & -0.886 & 0.379 \\
\hline Occupation & & & 0.269 & -0.060 & -0.540 & 0.591 \\
\hline Religion & & & 0.213 & 0.065 & 0.662 & 0.510 \\
\hline Politics & & & 0.278 & -0.138 & -1.225 & 0.225 \\
\hline Value & & & 0.256 & 0.294 & 2.956 & 0.004 \\
\hline Family & & & 0.213 & -0.385 & -3.905 & 0.000 \\
\hline Friendship & & & 0.226 & -0.044 & -0.415 & 0.680 \\
\hline Gender roles & & & 0.197 & 0.182 & 1.629 & 0.108 \\
\hline Sentimal relationships & & & 0.266 & -0.139 & -1.128 & 0.264 \\
\hline
\end{tabular}


(Table 7 to be continued)

\begin{tabular}{lrrrr}
\hline Rational style & 0.197 & -0.277 & -2.325 & 0.023 \\
Dependent style & 0.147 & -0.130 & -1.205 & 0.232 \\
Avoidant style & 0.182 & 0.423 & 3.070 & 0.003 \\
Intuitive style & 0.207 & 0.123 & 1.051 & 0.297 \\
Spontaneous style & 0.213 & -0.063 & -0.512 & 0.610 \\
\hline
\end{tabular}

Note. ${ }^{*} B=$ beta standardized coefficients.

In reference to the professional inefficacy, the predictive variables are age, occupation, religion, value, family, and the use of avoidant decision-making style (see Table 8).

Table 8

Model Summary of Hierarchical Regression Analysis That Predicts the Professional Inefficacy in All Group

\begin{tabular}{|c|c|c|c|c|c|c|}
\hline Measures & $R^{2}$ & Adjusted $R^{2}$ & S.E. & $B^{*}$ & $T$ & $p$-value \\
\hline Age & 0.692 & 0.625 & 0.045 & -0.250 & -3.153 & 0.002 \\
\hline Occupation & & & 0.185 & 0.221 & 2.384 & 0.020 \\
\hline Religion & & & 0.146 & -0.209 & -2.547 & 0.013 \\
\hline Politics & & & 0.192 & 0.032 & 0.338 & 0.736 \\
\hline Value & & & 0.176 & 0.185 & 2.210 & 0.031 \\
\hline Family & & & 0.147 & -0.352 & -4.245 & 0.000 \\
\hline Friendship & & & 0.156 & 0.065 & 0.722 & 0.473 \\
\hline Gender roles & & & 0.135 & 0.121 & 1.283 & 0.204 \\
\hline Sentimal relationships & & & 0.183 & 0.085 & 0.822 & 0.414 \\
\hline Rational style & & & 0.135 & 0.147 & 1.469 & 0.147 \\
\hline Dependent style & & & 0.101 & -0.042 & -0.461 & 0.646 \\
\hline Avoidant style & & & 0.125 & 0.496 & 4.275 & 0.000 \\
\hline Intuitive style & & & 0.143 & 0.015 & 0.152 & 0.880 \\
\hline Spontaneous style & & & 0.146 & 0.151 & 1.459 & 0.149 \\
\hline
\end{tabular}

Note. ${ }^{*} B=$ beta standardized coefficients.

Table 9

Model Summary of Hierarchical Regression Analyses That Predicts the Disillusion in All Ggroup

\begin{tabular}{|c|c|c|c|c|c|c|}
\hline Measures & $R^{2}$ & Adjusted $R^{2}$ & S.E. & $B^{*}$ & $T$ & $p$-value \\
\hline Age & 0.527 & 0.425 & 0.070 & 0.159 & 1.614 & 0.111 \\
\hline Occupation & & & 0.288 & -0.019 & -0.170 & 0.866 \\
\hline Religion & & & 0.228 & -0.136 & -1.343 & 0.184 \\
\hline Politics & & & 0.298 & -0.151 & -1.288 & 0.202 \\
\hline Value & & & 0.274 & 0.155 & 1.498 & 0.139 \\
\hline Family & & & 0.228 & -0.117 & -1.144 & 0.257 \\
\hline Friendship & & & 0.242 & -0.071 & -0.636 & 0.527 \\
\hline Gender roles & & & 0.210 & 0.272 & 2.330 & 0.023 \\
\hline Sentimal relationships & & & 0.284 & -0.048 & -0.371 & 0.712 \\
\hline Rational style & & & 0.210 & -0.546 & -4.401 & 0.000 \\
\hline Dependent style & & & 0.157 & -0.017 & -0.147 & 0.884 \\
\hline Avoidant style & & & 0.194 & -0.061 & -0.425 & 0.672 \\
\hline Intuitive style & & & 0.222 & 0.300 & 2.458 & 0.017 \\
\hline Spontaneous style & & & 0.227 & 0.088 & 0.685 & 0.496 \\
\hline
\end{tabular}

Note. ${ }^{*} B=$ beta standardized coefficients. 
Finally, the predictive variables of the sense of disillusion are only gender roles and the rational and intuitive styles (see Table 9).

\section{Discussion}

A number of researchers have investigated the relationship between leadership styles and decision-making processes and among teacher satisfaction, performance (Kirby, Paradise, \& King, 1992; Koh, Steers, \&Terborg, 1995; Silins, 1992), and teacher efficacy (Hipp, 1997; Hipp \& Bredeson, 1995). However, a crucial factor has not been incorporated in these investigations, namely, the perceptions of the teachers regarding their decision-making style and identity development.

The objectives of the present research are to measure the possible correlation among identity development, decision-making skills, and burnout in a group of middle school teachers, and identify predictive variables of the levels of burnout in the group of participants.

The first research hypothesis is confirmed, because results show that the teachers with a higher level of identity commitment seem to manifest a less emotional impairment related to their profession.

To confirm the second research hypothesis, the teachers who use the rational decision modalities seem to express lower level of burnout, and in particular, reduced depletion, deterioration, and emotional disillusionment. However, the teachers who use the decision-avoiding modalities, or who tend to postpone important choices, seem to show greater levels of exhaustion, emotional deterioration, and professional ineffectiveness. This result could be explained by the fact that subjects who tend to be more anxious, not only have a tendency to postpone the important choices for their life, but also, above all, will be more subject to the burnout. Similarly, the teachers who use a prevalent spontaneous decision-making style manifest greater exhaustion and sense of professional ineffectiveness.

To confirm the last research hypothesis, the high level of emotional exhaustion is predicted by the reduced tendency to attribute importance to the family, but high importance to religion and gender roles. These are joined by the reduced use of the rational style, but high utilization of avoidant and intuitive modalities. Similarly, predictors of the emotional deterioration are an elevated use of the avoidant style, but reduced rational style, and a greater importance attached to personal values, but reduced importance to family. Furthermore, predictors of the sense of professional inefficiency are a high age, the importance attributed to work, religion, and personal values, and the predominant use of a decision-avoidant style. Finally, the sense of disillusionment is predicted by the importance attributed to the gender role, the elevated use of an intuitive decision style, but reduced use of a rational style.

\section{Conclusion and Limitation}

Recent studies show that the burnout can be understood and addressed, only if we consider it as a problem that involves the entire organization, in which it manifests itself. Organizational dysfunctions can have a very significant weight in the onset of the syndrome. The organization, indeed, defines constraints and resources available to people.

It is in the working environment that relationships with others are structured and the rules that support them are defined. Thus, there are also structural, cultural, relational, and role aspects that have a strong impact on the incidence and degree of the burnout in an organization. Maslach and Leiter (2000) have identified six testable discrepancies in organizational life: overload work, lack of control, lack of gratification, the collapse of the sense of community belonging, lack of equity, and conflicting values. 
The image of the organization as a "machine" rationally oriented towards the achievement of predetermined purposes, as well as one that evokes the organicistic model, mainly aimed at merely adaptive dynamics as regards for the reference environment, for more than a decade has given way to a representation of the organizational phenomenon as a process governed by practices aimed at governing the unpredictability, the discontinuity, and the unexpected (Weick \& Sutcliffe, 2007).

The study presents some limitations. A limitation of the study is the cross-sectional measurement. It was not possible to test the causal relationships proposed in the theoretical framework. Despite this consideration, the use of structural equation analyses enabled us to demonstrate a series of hypotheses that were consistent with a causal theory.

A further limitation of the study was the use of convenience sampling methods for data collection. While cross-sectional convenience samples may prove useful in exploring theoretical models, such as the one built in the present study, caution should be exercised while generalizing the results beyond the current research. Furthermore, the identity development, the decision-making process, and the burnout level were measured through the use of self-report, which implies a risk of misleading information or social desiderability. Finally, results should be interpreted with caution due to the participants involved, in particular, because of the only presence of women teachers, which making generalizations difficult.

\section{References}

Avallone, F., \& Farnese, M. L. (2005). Culture organizzative: Modelli e strumenti ricerca e di intervento (Organizational culture: Models and tools research and intervention). Roma, Italy: Guerini Studio.

Balistreri, E., Busch-Rossnagel, N. A., \& Geisinger, K. F. (1995). Development and preliminary validation of the Ego Identity Process Questionnaire. Journal of Adolescence, 18(2), 179-192.

Di Nuovo, S., \& Commodari, E. (2004). Costi psicologici del curare: Stress e burnout nelle professioni di aiuto (Psychological costs of care: Stress and burnout in the helping professions). Bonanno (Ed.). Acireale, Roma.

Dworkin, A. G., Saha, L. J., \& Hill, A. N. (2003). Teachers burnout and perceptions of democratic school environment. International Educational Journal, 4(2), 108-120.

Edelwich, J., \& Brodsky, A. (1980). Burnout: Stages of disillusionment in the helping professions. New York, USA: Human Sciences Press.

Hipp, K. A. (1997). Documenting the effects of transformational leadership behavior on teacher efficacy. Paper presented at the Annual Meeting of the American Educational Research Association, I.L., Chicago, USA.

Hipp, K. A., \& Bredeson, P. V. (1995). Exploring connections between teacher efficacy and principals' leadership behaviors. Journal of School Leadership, 5, 136-150.

Kelly, G. A. (1955). The psychology of personal constructs. New York, USA: Norton.

Kirby, P. C., Paradise, L. V., \& King, M. I. (1992). Extraordinary leaders in education: Understanding transformational leadership. The Journal of Educational Research, 85(5), 303-311.

Koh, W. L., Steers, R. M., \& Terborg, J. R. (1995). The effects of transformational leadership on teacher attitudes and student performance in Singapore. Journal of Organization behavior, 16(4), 319-333.

Luyckx, K., Duriez, B., Theo, A., Klimsta, B., \& De Vitte, H. ( 2010). Identity statuses in young adult employees: Prospective relations with work engagement and burnout. Journal of Vocation Behavior, 77(3) 239-249.

Malizia, N. (2016). Abusi, violenze, maltrattamenti a scuola: Quando i bambini subiscono in silenzio (Abuse, violence, ill-treatment in school: When children suffer in silence). Torino, Italy: Giappichelli.

Maslach, C., \& Goldberg, J. (1998). Prevention of burnout: New perspectives. Applied and Preventive Psychology, 7(1), 63-74.

Maslach, C., \& Jackson, S. E. (1981). The Maslach burnout inventory. Palo Alto, C.A.: Consulting Psychologists Press.

Maslach, C., \& Jackson, S. E. (1984). Burnout in organizational settings. Applied Social Psychology Annual, 5, 133-153.

Maslach, C., \& Leiter, P. (2000). Burnout e organizzazione: Modificare i fattori strutturali della demotivazione al lavoro (Burnout and organization: To change the structural factors of motivation at work). Milano, Italy: Feltrinelli. 
Pellerone, M. (2014). Interpersonal adjustment, personal resources, aptitudes, and interests: Vocational decision-making process in a group of Italian adolescents. US-China Education Review B, 4(9), 648-655.

Pellerone, M., Passanisi, A., \& Bellomo, M. F. P. (2015). Identity development, intelligence structure, and interests: A cross-sectional study in a group of Italian adolescents during the decision-making process. Journal of Psychology Research and Behavior Management, 8, 239-249.

Pines, A., Aronson, E., \& Kafry, D. (1981). Burnout: From tedium to personal growth. New York, USA: The Free Press.

Pithers, R. T., \& Fogarty, G. J. (1995). Occupational stress among vocational teachers. British Journal of Educational Psychology, 65(1), 3-14.

Santinello, M., \& Altonoè, G. (2007). Il Link Burnout Questionnaire (The Link Burnout Questionnaire). Firenze, Italy: Organizzazioni Speciali.

Scott, S. G., \& Bruce, R. A. (1995). Decision-making style: The development and assessment of a new measure. Educational and Psychological, 55(5), 818-831.

Silins, H. C. (1992). Effective leadership for school reform. The Alberta Journal of Educational Research, 38(4), 317-334.

Specchiale, A., Attinà, A. N., De Maria, G., Sapienza, I., Sarrafiore, A., Nicotra, R., Massimino, S., Petralia, M. C., \& Ramaci, T. (2013). Pilot Study on the role of psychosocial aggression in a sample of cops and robbers. Acta Medica Mediterranea, 29, 407-410.

Weick, K., \& Sutcliffe, K. (2007). Managing the unexpected: Resilient performance in an age of uncertainty. San Francisco, USA: John Wiley \& Sons Inc.. 